\title{
Application of Data Mining Method Using Association Rules Apriori To Shopping Cart Analysis On Sale Transactions (Case Study Alfamidi Burnt Stone)
}

\author{
Vanessa Siregar, Paska Marto Hasugian \\ ${ }^{1.2}$ Informatics Engineering Study Program, STMIK Pelita Nusantara, Jl. Iskandar Muda No. 1 \\ Medan, North Sumatra, Indonesia 20154 \\ E-mail:vanessasiregar15@gmail.com
}

Abstract-Also Often data mining is called knowledge discovery in databases (KDD), ie activities include the collection, historical use of data to find regularities, patterns or relationships in data sets with a large size. The company may be interested to know if some groups consistently goods items purchased together. This study analyzes the transaction of data information retrieval from the sale of skin care and hair care using data mining algorithms priori Alfamidi Burnt Stones with the highest support value is $8 \%$ and the highest value is 5\% confidance

Keywords: Data mining, a priori algorithm.

\section{Introduction}

Data mining is the process of learning the techniques of computer processing (machine learning) for analyzing and extracting knowledge (knowledge) automatically. Data mining is often also called knowledge discovery in databases (KDD), the activity is the collection, use historical data to provide regularity, patterns or relationships in large data sets. The end result of data mining can be used to improve decision making in the future. One area of application of data mining is the important PT.Alfamidi. If the goods are not suitable placement may lead to irregular levels of consumers to spend a lot of waktub, then from that data mining can be applied in order to change the decision that will come.

\section{Theory}

\subsection{Data Mining}

Data mining is mengekstrasikan knowledge from large data sets, data mining is a combined technique of data analysis methods sustained by algorithms in processing large amounts of data.

\subsection{Apriori algorithm}

Priori algorithm is a kind of association rules in data mining. Besides a priori, which included agolongan pad is the method of Generalized Rule Induction and Hash Algorithm Based. That is a rule that states the association between some of the attributes which is often called affinity analysis or market basket analysis. The rules of association which is a data mining technique can find the rules of associative between a combination of items.

Several stages in the association analysis.

a. High frequency pattern analysis

looking for a combination of items that meet the minimum requirements. with the formula

$$
\text { Support } \mathrm{A}=\frac{\text { Jumlah transaksi mengandung A }}{\text { Total transaksi }}
$$

While the two or more itemsets obtained by the formula:

b. The formation of associative rules

Support A,B =

$\underline{\text { Jumlah transaksi mengandung A dan B }}$

Finding association rules that meet the minimum requirements for confidence by calculating confidence associative rules $\mathrm{AB}$. by the formula: 


\section{Jumlah transaksi mengandung A dan B \\ Jumlah transaksi mengandung A}

Of the process of formation of association rules it will obtain the confidence value of each item set, and then set the minimum value to gain confidence association rules.

\section{Research methods}

Methodology is a framework in conducting research. The framework of the study are:

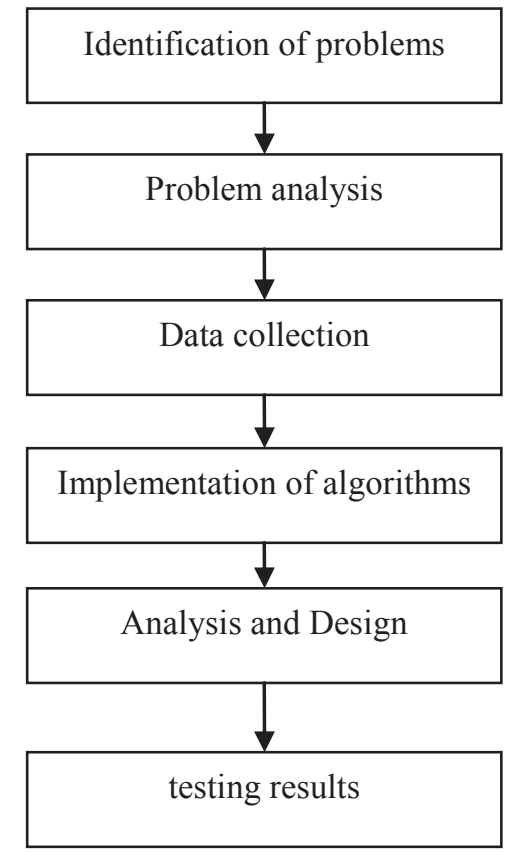

Picture 1. Framework Research

\section{Analysis and Design}

In this study, the data was analyzed transaction data in January 2018 against 25 transaction data consists of 50 items.

Table 1.

List of skin care products

\begin{tabular}{lll}
\hline No. & Product code & Product name \\
\hline 1 & A01 & Ponds Pw pr.WHT 100ml \\
2 & A02 & Ponds Pw.bt $100 \mathrm{ml}$ \\
3 & A03 & Ponds pw nght $20 \mathrm{ml}$ \\
4 & A04 & Ponds oily pw day $20 \mathrm{ml}$ \\
5 & A05 & Ponds plmb wht. Bs $20 \mathrm{ml}$ \\
6 & A06 & Ponds mgc pwd mm $50 \mathrm{ml}$ \\
7 & A07 & Shinzui kirei $110 \mathrm{ml}$ \\
8 & A08 & SBN Shinzui knsh $85 \mathrm{~g}$ \\
9 & A09 & Shinzui b / c mats 450g \\
10 & A10 & Lfebuoy MLD CR $60 \mathrm{G}$ \\
11 & A11 & Lifebuoy 450g bw LMN \\
12 & A12 & Lc Grnier crm yuzu 20 ml \\
13 & A13 & Grnier M. cool foam 50ml \\
14 & A14 & Pnk mc.cln Grnier $125 \mathrm{~g}$ \\
15 & A15 & Grnier anco fight $100 \mathrm{~g}$ \\
16 & A16 & Grnier cur / w day $20 \mathrm{~g}$ \\
\hline
\end{tabular}




\begin{tabular}{lll}
\hline No. & Product code & Product name \\
\hline 17 & A17 & Grnier cur / w fm 50ml \\
18 & A18 & Grnier men w + o / c 100ml \\
19 & A19 & Fair \& lovely f.fm 50ml \\
20 & A20 & F \& lovely m.vit crm $50 \mathrm{ml}$ \\
21 & A21 & Vienna p.off mask $15 \mathrm{ml}$ \\
22 & A22 & Marina ntr.fresh $200 \mathrm{ml}$ \\
23 & A23 & Wardah w.scrt fw $100 \mathrm{ml}$ \\
24 & A24 & Nivea r / on ext / wht 50ml \\
25 & A25 & Biore b.foam jsmw $250 \mathrm{ml}$ \\
\hline & & Source: Research (2019)
\end{tabular}

Table 2.

List of hair care products

\begin{tabular}{lll}
\hline No. & Product code & Product name \\
\hline 26 & B1 & Sunslik black shp 170 ml \\
27 & B2 & Sunslik black shp 340 ml \\
23 & B3 & Sunslik shp soft and s 70 ml \\
29 & B4 & Cnd Sunslik blck 170 ml \\
30 & B5 & 170 ml soft cnd Sunslik \\
31 & B6 & Sunslik re hijb shp 170 ml \\
32 & B7 & Ssc shp 135ml Pantene \\
33 & B8 & Pantene shp ant / D 170 ml \\
34 & B9 & Pantene shp hr / fl 70 ml \\
35 & B10 & Pantene ssc shp 150 ml \\
36 & B11 & Pantene cdtnr TDC 135 ml \\
37 & B12 & Emeron hbl w. mul 250 ml \\
38 & B13 & Trsemme shp dc \& P 170 ml \\
39 & B14 & F \& N hijb frs mid 100ml \\
40 & B15 & Nature p / rmb rntk 140 ml \\
41 & B16 & Lifebuoy shp a / d 70 \\
42 & B17 & Lifebuoy shp a / d 170 ml \\
43 & B18 & Lifebuoy soft shp 70 ml \\
44 & B19 & m / z hair eng RYL 30 g \\
45 & B20 & H.vit ellipse k / sil 65g \\
46 & B21 & Dove r / on shp 40 ml \\
47 & B22 & Rejoice 3in1 170 shp \\
48 & B23 & Serasoft shp d / trtmen 170 ml \\
49 & B23 & Clear shp D / 150 ml \\
50 & B25 & Clear shp a / d 320 ml \\
\hline & &
\end{tabular}

\section{a. Pattern Frequency 1 item}

Given the value of the support of at least $8 \%$ of 25 transactions and then do a search on a support value of each item with the formula. Support the value of an item obtained by the following formula.

$$
\text { Support } \mathrm{A}=\frac{\text { Jumlah transaksi mengandung A }}{\text { Total transaksi }}
$$

Support Ponds Pw pr. WHT 100ml

$$
=\frac{4}{25} \times 100 \%=16 \%
$$

Table 3.

\begin{tabular}{|c|c|c|c|c|}
\hline No. & Product code & $\begin{array}{l}\text { Name } \\
\text { Product }\end{array}$ & amount & $\begin{array}{l}\text { value } \\
\text { Support }\end{array}$ \\
\hline 1 & $\mathrm{~A} 01$ & Ponds Pw pr.WHT $100 \mathrm{ml}$ & $4 / 25=0: 16$ & $16 \%$ \\
\hline 2 & $\mathrm{~A} 03$ & Ponds Pw night $20 \mathrm{ml}$ & $2 / 25=0: 08$ & $8 \%$ \\
\hline 3 & A13 & Grnier M. cool foam $50 \mathrm{ml}$ & $2 / 25=0: 08$ & $8 \%$ \\
\hline 4 & A15 & Grnier anco fight $100 \mathrm{~g}$ & $2 / 25=0: 08$ & $8 \%$ \\
\hline 5 & A16 & Grnier cur / w day $20 \mathrm{~g}$ & $2 / 25=0: 08$ & $8 \%$ \\
\hline 6 & A24 & Nivea $\mathrm{r} /$ on ext / wht $50 \mathrm{ml}$ & $2 / 25=0: 08$ & $8 \%$ \\
\hline 7 & B1 & Sunslik black shp $170 \mathrm{ml}$ & $2 / 25=0: 08$ & $4 \%$ \\
\hline 8 & B7 & Ssc shp $135 \mathrm{ml}$ Pantene & $3 / 25=0: 12$ & $12 \%$ \\
\hline
\end{tabular}

Support 1-itemset meet 